\title{
The Use of Gold in Autocatalytic Plating Processes
}

\author{
W. S. Rapson and T. Groenewald \\ Research Organisation, The Chamber of Mines of South Africa, Johannesburg
}

Certain electroless gold plating procedures are autocatalytic in nature, while gold can also be used as an activator or initiator in the autocatalytic plating of plastics and of other non-conducting materials by metals such as nickel and copper. This paper describes the scientific basis of autocatalytic plating, and reviews electroless gold plating procedures. The effectiveness of gold as an activator in the autocatalytic plating of plastics is also briefly surveyed.

The literature relating to so-called "electroless" plating is confusing, not only because it tends to be largely of an empirical nature, but also because the term "electroless" has often been used to describe processes which are different in character. True "electroless" or autocatalytic plating should not be confused either with electrochemical displacement deposition, or with homogeneous chemical reduction processes, such as silvering. In the former, deposition is accompanied by dissolution of the basis metal, which must therefore be less noble than the metal being plated. It does not, therefore, occur on gold. Moreover, deposition ceases immediately access of plating metal ions to the basis metal is not possible. Only thin platings can therefore be expected by this procedure. In the latter, deposition occurs indiscriminately over all objects in contact with the solution. After initial deposition has occurred, however, autocatalytic deposition may constitute the main plating process.

\section{Introduction of the Process}

The first autocatalytic plating process was that invented by Brenner and Riddell (1) in 1946 for the "electroless" plating of nickel. Its distinguishing feature was that deposition of nickel on steel was achieved by immersion of the steel in an ammoniacal solution containing a nickel salt together with hypophosphites. The formation of nickel was confined to the surface of the steel, and took place as a result of a reduction of the nickel salt by the hypophosphite, which was heterogeneously catalysed by the metal surface, and specifically by the metal itself. This nickel plating process rapidly found application in practice $(2,3,4)$.

Since this discovery, similar autocatalytic plating processes have been developed for a number of metals, both singly and in combination, and have become important as supplements or alternatives to electroplating in a number of circumstances. Thus they provide a means of depositing, on articles of complex shape, uniformly thick coatings that are relatively fine grained, pore free, and corrosion resistant.

In the case of articles made of an active metal, an initial deposit of the catalytically active metal being plated is formed by electrochemical displacement, after which autocatalytic deposition takes over. In other cases, a brief cathodic pulse may be required to deposit sufficient catalytic metal from the solution to initiate the reaction. This can be achieved either by an external power source, or by contact (below solution level) with an active metal such as aluminium which forms a local galvanic cell with the basis metal.

In the case of non-metallic and non-conducting articles such as plastics, initiation of reaction is achieved by adsorbing a reducing agent on the substrate, and then immersing it in a solution of some other metal such as palladium or gold, which is easily reduced and initiates the plating of the desired metal. This procedure, still imperfectly understood, is the basis of the considerable industry based today upon the plating of plastics. The pre-treatment of the surface of the plastic by "sensitisation" and "activation" is an important step in the procedure in each instance. Such pre-treatment must not only promote the adsorption of the reducing agent (usually a stannous salt) on the surface, and the deposition of the activating palladium or gold catalyst, but must also etch the plastic surface so that the metal plating is "keyed" to it. The pre-treatment will therefore vary not only from plastic to plastic but may also vary in its effectiveness according to the method of production of even one type of plastic. 
So far as gold is concerned, autocatalytic plating is therefore of interest from two points of view, namely:

(a) The development of processes for the autocatalytic plating of gold. Although a variety of processes has been described for the chemical deposition of thin gold coatings on basis metals, and although a number of proprietary preparations are available for this purpose, the available information relating to them indicates that they are mostly not truly autocatalytic. In fact, as we shall see, it is only relatively recently that the first truly autocatalytic processes for plating of gold have been described.

(b) The possible development of the use of gold as an activator in the plating of plastics. Gold is effective as an activator, but circumstances have so far favoured the use of palladium activators in industrial practice.

As a preliminary to a discussion of these two matters, it is appropriate to review briefly the scientific basis of autocatalytic plating.

\section{The Scientific Background to Autocatalytic Plating}

The basic reaction can be represented in the simple case where the oxidation state of the metal in the plating solution is one, as

$$
M^{+}+\operatorname{Red} \underset{\text { catalyst }}{\stackrel{M}{\longrightarrow}} M+O x
$$

or more generally, in the case of metals in higher oxidation states $\mathrm{n}$, by two half redox reactions

$$
\begin{aligned}
\mathrm{nRed} & \longleftrightarrow \mathrm{nOx}+\mathrm{ne}^{-} \\
\mathrm{M}^{\mathrm{n}+}+\mathrm{ne}^{-} & \longleftrightarrow \mathrm{M}
\end{aligned}
$$

where $M$ is the metal being plated and Red represents a reductant, which for the sake of simplicity is represented as being transformed in the process into $\mathrm{Ox}$, the oxidised state, by transfer of a single electron.

In practice the metal $M$ is usually present in the plating solution in complexed form, and the concentration of $\mathrm{M}^{\mathrm{n}+}$ ions in the plating solution is determined by the stability constant of the complex, and the concentration of the complexant.

Redox reactions of the above type are often catalysed by metallic surfaces and it has been suggested (5) that the role of the metal in such instances is simply that of a conductor of electrons, accepting the electrons released in the first stage of the reaction from the reductant at one point on its surface, and releasing them to the oxidant in the second stage at another point thus:

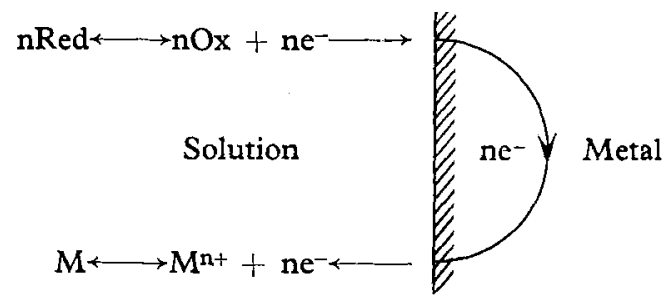

In brief the position in an autocatalytic plating reaction is that we have at the conducting metal surface two separate redox reactions occurring, each of which strives to establish its own equilibrium potential on the metal.

Electrochemical theory (6-10) predicts that in a situation such as this a steady state will be established with the metal at what is termed a steady state mixed potential $E_{M P}$, the exact value of which will be determined by the shapes of the current densitypotential and Tafel curves for the two electrode processes which are involved.

The characteristics of this steady state mixed potential are the following:

(a) both redox systems are removed from their own characteristic equilibrium potentials;

(b) net electrochemical reaction therefore occurs in each redox system;

(c) the condition for the steady state is that the sum of the cathodic current densities is equal to the sum of the anodic current densities, for the system is an isolated one.

The situation is illustrated schematically in Figure 1, taken from Paunovic (9) of Photocircuits Corporation. This shows Tafel lines for a system with two different simultaneous electrochemical reactions. At the steady state, in terms of $(c)$ above $\overrightarrow{i_{M}}+\overrightarrow{i_{R e d}}=\dot{i}_{M}+\dot{i}_{\text {Red }}$. For large values of the anodic or cathodic polarisation $\eta$, however, $i_{M}$ can be neglected in comparison with $\overrightarrow{i_{M}}$, and $\overrightarrow{i_{R e d}}$ in comparison with $\dot{i}_{\text {Red }}$, and the condition for the steady state potential reduces to $\overrightarrow{i_{M}}=\overrightarrow{i_{\text {Red }}}$. The rate of deposition of metal is equal to the rate of oxidation of the reducing agent. As will be apparent from Figure 1, therefore, if the current-potential functions are known for the individual electrode processes, $\mathrm{E}_{\mathrm{MP}}$ can be plotted and the rate of deposition calculated from the value $\left(i_{\mathrm{dep}}\right)$ of $i$ at this potential.

The rates of deposition at potentials away from the steady state mixed potential can likewise be deducedsuch potentials being achieved of course under the influence of an external potential source.

\section{Factors Affecting Autocatalytic Plating Reactions}

From the above it will be clear that the factors which affect the current-potential relationships for the partial redox reactions involved will affect the values of $E_{M P}$ and $i_{\text {dep }}$. They will in fact determine whether autocatalytic plating will occur, and if so, at what rate.

The main such factors are the equilibrium potentials for the partial redox reactions, their exchange 
Fig. 1 Current-potential curves for a system with two different simultaneous electrochemical reactions. (After Paunovic)

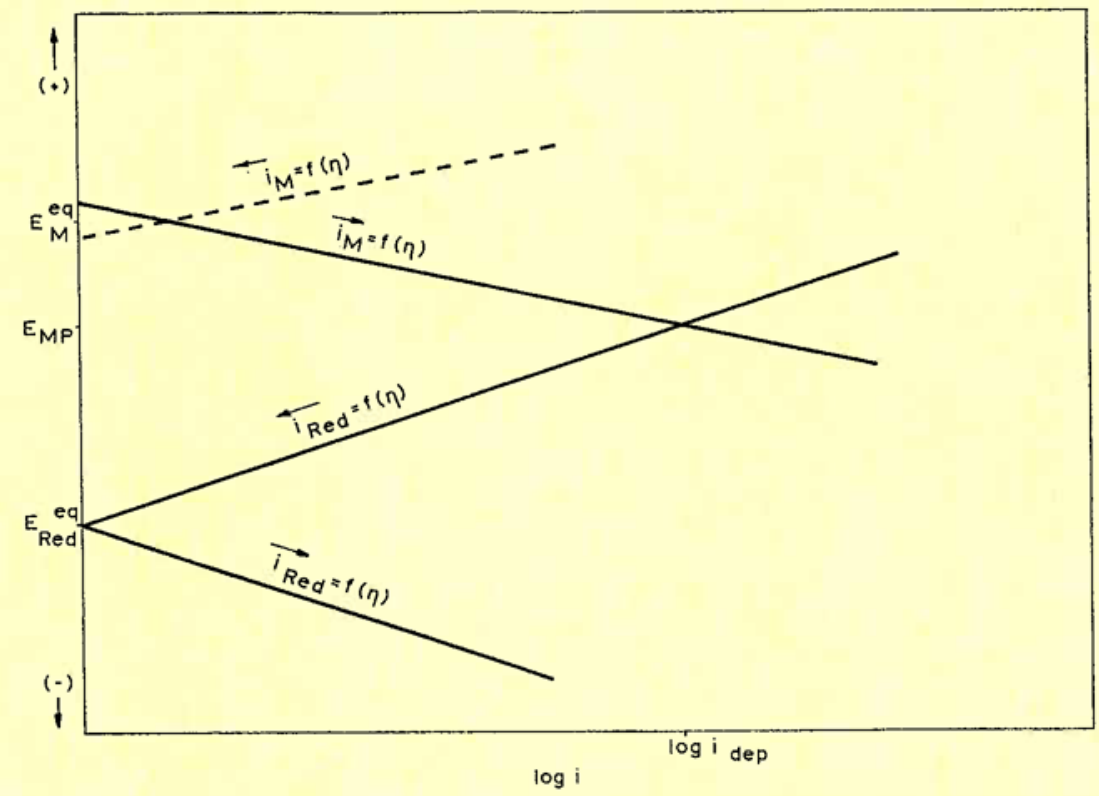

current densities and their transfer coefficients on the metal in question, the temperature, the types of overvoltage effects and the presence of addition agents.

\section{Exchange Current Densities}

The effect of exchange current density upon $\mathrm{E}_{\mathrm{MP}}$ and $i_{\mathrm{dep}}$ is illustrated in Figure 2, after Paunovic (9). It is shown here how changes in the exchange current density $i_{o}$ of one of the redox reactions affects the values of $E_{M P}$ and $i_{\text {dep }}$ at a metal surface at which two redox reactions are occurring.
The importance of this exchange current density effect is underlined by the work of Spiro and Ravnö (10) at Imperial College, London, on heterogeneous catalysis in solution. These investigators drew attention in 1965 to the dependence of catalysis upon the electrochemical reversibilities of the two redox reactions involved in catalytic reactions of this type and to the fact that these reversibilities could be measured quantitatively in terms of the corresponding exchange current densities at the metal surface.

In a study of the effects of platinum on a large number of oxidation-reduction reactions, they esti-
Fig. 2 The effect of changes in the exchange current density (i.e. in the reversibility) of one of the redox reactions on the mixed potential and the rate of the auto-catalytic deposition.

(After Paunovic)

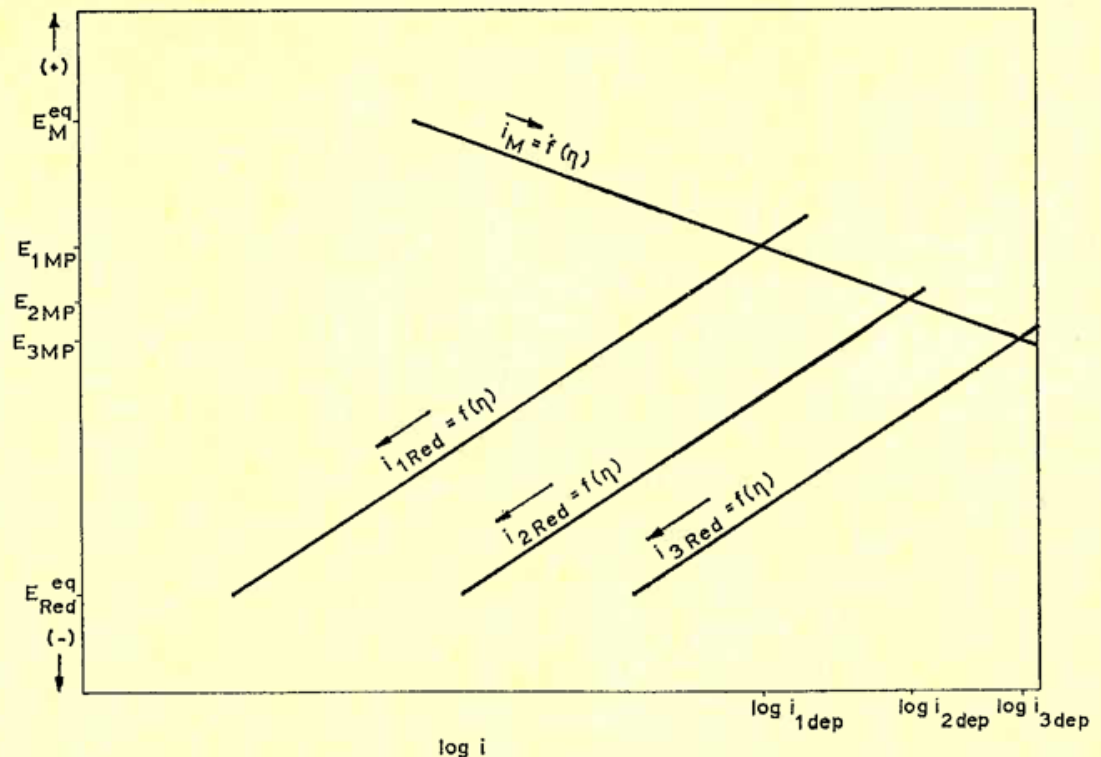

$\log \mathrm{i}$ 
mated $i_{0}$ values from simple current-voltage curves and from e.m.f. behaviour, and in this way were able to confirm that catalytic effects occurred:

(i) when $\dot{i}_{0}$ values were such as to indicate that the half redox reactions were reversible; and

(ii) when only one of the redox reactions was reversible and the difference between the reduction potentials of the two redox reactions was at least $0.5 \mathrm{~V}$.

They analysed conditions in such reactions, and interpreted their results by reference to three curves of current density against electrode potential for three independent redox couples of platinum electrodes (Figure 3).

The slopes of these curves where they cross the zero current axis can be shown to be proportional to the exchange current density of the couple concerned, so that $P Q R$ represents a fairly irreversible couple, whereas $\mathrm{ABC}$ and $\mathrm{DEF}$ correspond to reversible couples. Where two reversible couples such as $A B C$ and $D E F$ are present together, the current density-voltage curves are steep, and at the mixture potential the anodic and cathodic currents are large, so that a rapid heterogeneous reaction can be expected. Where one couple is reversible (ABC or $\mathrm{DEF})$ and the other irreversible (PQR), however, it will be seen that the mixture potential is in each case much closer to the e.m.f. of the reversible couple (B or E), than to that of the irreversible one (Q). Moreover the current ( $\mathrm{ab}$ or de) at the mixture potential is smaller than that (st), but nevertheless appreciable. Heterogeneous reaction between two couples can therefore be fast even if one is irreversible, and it can be shown that the reaction rate increases the further apart the e.m.f.s of the two couples. Finally, where both couples are irreversible it will be apparent that the situation will be similar to that where only one couple is irreversible, except that the mixture potential will be now some distance away from the e.m.f.s of the individual couples, and the current density at the mixture potential will be small unless the two e.m.f.s are far apart.

Comparison of the results of this analysis by Spiro and Ravnö with their experimental findings recorded above, underlines the importance of the degree of the reversibility of the two couples, as reflected by their exchange current densities, and of the magnitude of the difference between their redox potentials, in determining whether or at what rate they will bring about autocatalytic reaction when in combination.

\section{Concentration of Reactants}

Exchange current density is dependent on the concentrations of reactants, which affect the rate of autocatalytic deposition accordingly. Thus for

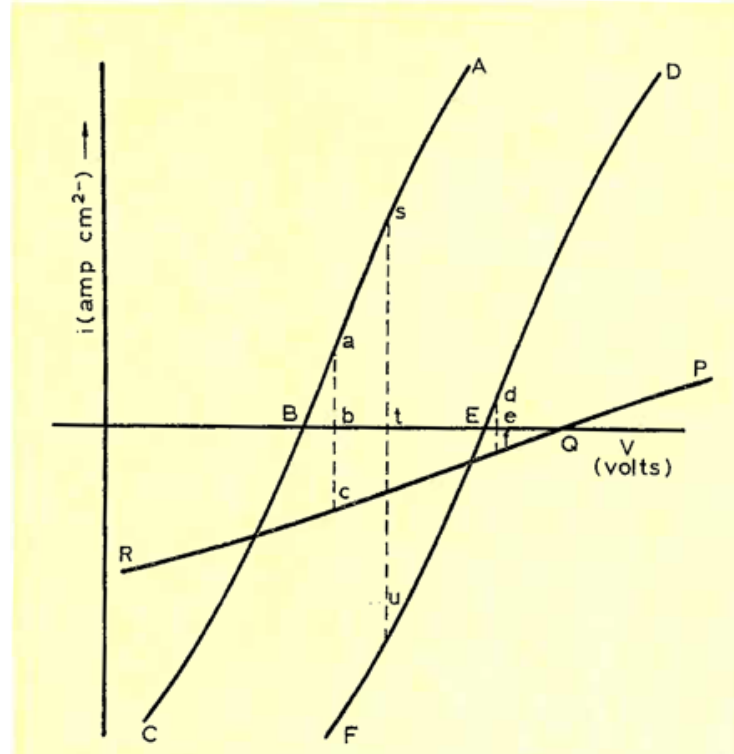

Fig. 3 Schematic diagram of current densityvoltage curves for two reversible couples (ABC, DEF) and one irreversible couple (PQR). (After Spiro and Ravnö)

reaction (1) (on page 120) this dependence is given by the equation

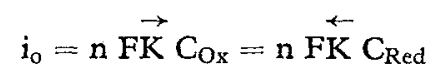

$$
\rightarrow \quad r
$$

where $\mathrm{K}$ and $\mathrm{K}$ are the rate constants for the forward and reverse reactions and $\mathrm{C}_{\mathrm{Ox}}$ and $\mathrm{C}_{\mathrm{Red}}$ are the concentrations of $\mathrm{Ox}$ and Red respectively. With changes in $i_{0}$, the current-potential relationships $i=f(\eta)$ for the reaction alters also (cf. Fig. 2).

Similar effects follow on changes in concentration of the metal ions $\mathrm{M}^{\mathrm{n}}+$ in the plating medium.

In practice other effects may be superimposed upon these. Thus it is a matter of experience that if the concentrations of metal ions or reductant are made too high in the plating medium the rate of the homogeneous redox reaction may become significant, and there is then a risk that metal may be precipitated throughout this medium and not solely on the surface to be plated. It is for this reason, as well as from solubility considerations generally, that a complexant is normally added. The metal ion concentration is then controlled as already mentioned, by the stability of the complex ion which is formed, and the concentration of the complexant-provided, of course, that the complex ion itself does not promote the homogeneous redox reaction.

As a result of the use of complexants, other effects may also arise. Thus in the autocatalytic deposition of gold from cyanide solutions, using borohydride as the reductant, the deposition rate 
increases with $\mathrm{KAu}(\mathrm{CN})_{2}$ concentrations to a maximum and subsequently decreases. This has been interpreted (11) as due to competitive adsorption of $\mathrm{Au}(\mathrm{CN})_{2}^{-}$and $\mathrm{BH}_{3} \mathrm{OH}^{-}$(the effective reductant) on the substrate surface prior to the redox reaction.

\section{Temperature}

The rate constants in equation (3) are subject to the normal Arrhenius effect, and positive temperature effects on plating rates are therefore observed. These are most important in practice.

\section{Addition Agents}

The use of complexing agents in autocatalytic plating solutions may affect the deposition of metal, not only as a result of the control exercised over metal ion concentrations, but also as a result of the adsorption of the metal complex ion or the complexant on the metal surface. An example of this has been quoted above, and in general the rates of the electrode reactions can be envisaged as being affected as a result of adsorption of complex ions, complexing agents or other additives in two ways. They are:

(a) A decrease in surface available for the electrode reactions. This results in an increase in actual current densities and therefore in overvoltage.

(b) A new slow step-namely transport of reactants through the adsorbed film-may be introduced into the process.

This brings us to a consideration of overvoltage effects.

\section{Overvoltage Effects}

Rates of autocatalytic deposition as determined by the current density are of course subject to limitations in the rates of any one of the consecutive electrode processes, such as charge transfer, mass transport of reactants or products of reaction, and reactions which precede or follow charge transfer.

Figure 4, from Paunovic, illustrates how the rate of autocatalytic deposition and the mixed potential are affected by such different limitations.

\section{Effects of Agitation}

The effects of agitation are of interest in relation to these overvoltage effects, since agitation could be expected to reduce the effects on reaction rates of limitations in mass transfer rates.

In practice agitation of baths during autocatalytic plating is common practice, and is based upon the improvements in uniformity of deposition and in plating rates achieved in electrolyte deposition. The effects of agitation upon these factors in autocatalytic plating, however, have been reported to be dependent (12) on concentrations, temperature, and the activa-

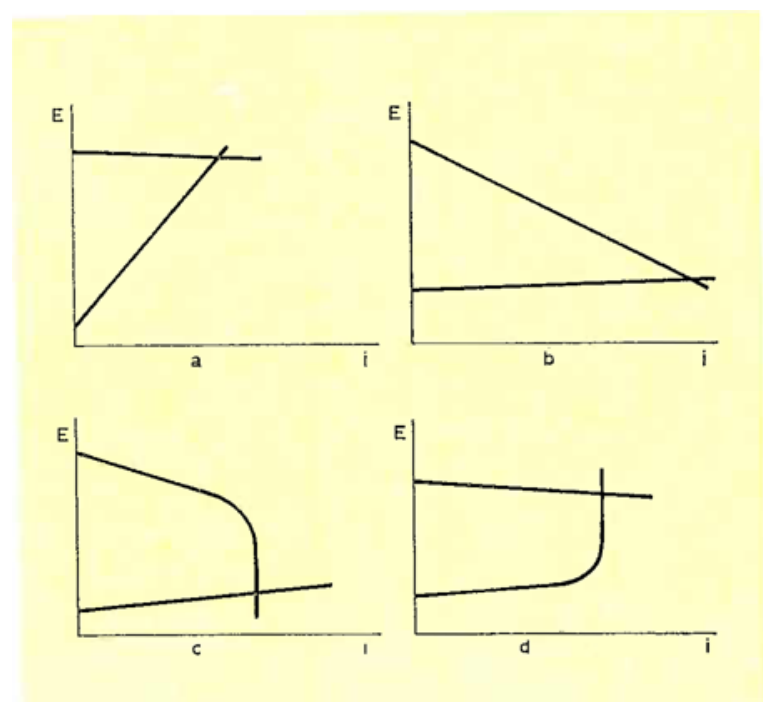

Fig. 4 Dependence of the rate of electroless deposition and the mixed potential upon the type of overvoltage. (After Paunovic)
(a) Control by anodic charge transfer reaction
(b) Control by cathodic charge transfer reaction
(c) Control by diffusion of eathodic (Ox) reactant
(d) Control by diffusion of anodic (Red) reactant

tion energy of the chemical reaction involved, and the deposition rate found to be either enhanced or impaired depending on a number of parameters.

\section{Sile Reactions}

Where hypophosphites are used as the reducing agent, deposition of phosphorus with the metal may occur. This is particularly significant in the autocatalytic plating of nickel and cobalt using hypophosphites, where the product always contains phosphorus in amounts of 2.5 to 14 per cent. Scholder and Heckel (13) have noted that the phosphorus is present in the precipitate as phosphides and that the phosphorus content of the deposit increases with increases in the acidity of the plating medium.

Similarly, boron may be deposited in small amounts with the metal when borohydrides are used as reducing agents.

In general, however, the most generally observed side reaction during autocatalytic plating is the evolution of hydrogen and the ratio hydrogen evolved/ metal plated is a significant one in practice.

\section{Changes in Bath Composition}

Apart from depletion of metal and reductant, the most significant effect of bath usage on bath composition is the increase in acidity caused by the acid generated during the reaction.

Buffering agents may therefore be added to the plating bath to counter this effect. Such buffering 
agents may, however, have other effects in the process.

\section{General Conclusion}

In view of the number of factors which affect the process, and the complexity of their interactions, it is not surprising that much of the literature relating to the formulation of plating baths has an empirical flavour, and that the development of plating baths has outstripped detailed understanding of the reaction mechanisms involved in them.

\section{Electroless Plating of Gold}

A number of "electroless" gold plating solutions, some of them proprietary, have been described and/or are on the market. They have been reviewed by Okinaka (14), who has stressed that, in a number of instances, it is by no means clear whether the processes are autocatalytic or not. At the one extreme there are solutions which clearly effect plating by electrochemical displacement. They give rise to thin coatings only, and will not plate gold itself. In between such solutions, however, and the borohydride baths which are truly autocatalytic, there are "electroless" gold baths which deposit gold on basis metals such as copper and nickel at fast rates and to considerable thicknesses. Nevertheless, they do not plate gold itself, so that these plating processes cannot be truly autocatalytic.

Okinaka notes three possibilities which could explain the behaviour of such baths, namely:

(i) the reaction is an electrochemical displacement and produces a porous deposit,

(ii) the basis metal acts as a catalyst, but gold does not, and the deposit is porous,

(iii) the reaction is indeed autocatalytic, but only the freshly deposited gold is active as a catalyst.

The studies of the processes in this category which have been reported do not, however, provide a basis for testing these possibilities. That the latter possibility is a real one is indicated by a recent observation by Groenewald (15) of a catalytic effect of gold which is operative only when the gold is freshly deposited.

\section{Types of Electroless Gold Baths}

The following types of electroless gold baths are discussed by Okinaka (14) and by Goldie (16):

\section{Hypophosphite Baths}

These include:

(i) The Swan and Gostin bath (17-20);

(ii) The Brookshire bath (21);

(iii) The Ezawa and Ito pure gold bath (22); (iv) The Ezawa and Ito gold-nickel alloy bath (23).

\section{Hydrazine Baths}

These include:

(i) The Gostin and Swan bath (24);

(ii) The Luce bath (25).

The Diethylglycine Baths of Walton et al. $(26,27)$

These employ citric and/or tartaric acids in addition to diethylglycine as reducing agents.

\section{Other Baths}

The ammonia baths of Schnable, McCormack and Zeblinsky (28);

The thiourea bath of Oda and Hayashi (29);

The borohydride bath of Okinaka et al. (30-37);

The dimethylamine borane bath of McCormack (38);

The aldehyde-amine borane bath of Rich (39);

The early formaldehyde baths of Wein (40);

Baths using unstable organogold compounds (41).

Information relating to the composition of the various proprietary electroless gold solutions which are marketed today is lacking.

Of the above baths, those based upon the use of borohydrides have been investigated and reported upon in greatest detail and more detailed reference to them seems justified.

\section{The Borohydride Baths of Okinaka et al.}

Bath compositions can be varied over a considerable range, but the following is typical: $\mathrm{KAu}(\mathrm{CN})_{2}$ $(0.03 \mathrm{M}), \mathrm{KCN}(0.1 \mathrm{M}), \mathrm{KOH}(0.2 \mathrm{M}), \mathrm{KBH}_{4}$ $(0.2 \mathrm{M})$. Such a bath, operated at $70^{\circ} \mathrm{C}$, can give plating rates of up to $6 \mu \mathrm{m} / \mathrm{h}$. (42).

Since the hydrolysis of the $\mathrm{BH}_{4}^{-}$ion according to the overall equation

$$
\mathrm{BH}_{4}^{-}+2 \mathrm{H}_{2} \mathrm{O} \rightarrow \mathrm{BO}_{2}^{-}+4 \mathrm{H}_{2}
$$

is catalysed by acids, an important role of the $\mathrm{KOH}$ in the bath is to stabilise it against decomposition during storage. The deposition rate of the gold is, however, lower at the higher $\mathrm{KOH}$ concentrations at all levels of gold concentration, so that a compromise has to be effected in the formulation of solutions in practice.

The effect has its origin in the fact that the hydrolysis of the $\mathrm{BH}_{4}^{-}$ion is progressive, and occurs essentially in two steps (43-45):

$$
\begin{aligned}
& \mathrm{BH}_{4}^{-}+\mathrm{H}_{2} \mathrm{O} \rightarrow \mathrm{BH}_{3} \mathrm{OH}^{-}+\mathrm{H}_{2} \\
& \mathrm{BH}_{3} \mathrm{OH}^{-}+\mathrm{H}_{2} \mathrm{O} \rightarrow \mathrm{BO}_{2}^{-}+3 \mathrm{H}_{2}
\end{aligned}
$$

with the $\mathrm{BH}_{3} \mathrm{OH}^{-}$being the species responsible for 
the reduction. Its concentration during deposition is only 2 per cent or less of the initial $\mathrm{BH}_{4}^{-}$concentration. The efficiency of utilisation of $\mathrm{KBH}_{4}$ in the process is therefore low.

The deposition rate increases to a maximum and subsequently decreases. This has been interpreted as due to competitive adsorption of $\mathrm{Au}(\mathrm{CN})_{2}{ }^{-}$and $\mathrm{BH}_{3} \mathrm{OH}^{-}$in the substrate surface prior to the redox reaction.

In tune with this is the observation that small amounts of $\mathrm{Ni}(\mathrm{CN})_{4}{ }^{-}$in the plating bath drastically reduce gold deposition rates, the effect being interpreted as due to interference by this ion also with $\mathrm{BH}_{3} \mathrm{OH}^{-}$adsorption on the gold surface. This means that gold deposition rates on nickel are low, since initial deposition of gold on nickel occurs by displacement, nickel going into solution, as $\mathrm{Ni}(\mathrm{CN})_{4}{ }^{-}$.

While the deposition rate is consistently higher at lower KCN concentrations, the presence of excess free cyanide is reported as essential for bath stability. Presumably the KCN acts also as a buffer. In its absence metallic gold is liberated even at room temperature.

Above $85^{\circ} \mathrm{C}$ the baths decompose rapidly. Up to that temperature, however, deposition rates approximately double for each $10^{\circ} \mathrm{C}$ increase in temperature, the corresponding Arrhenius plot yielding a straight line.

The instability of the baths can be exploited to recover the gold from used baths. On boiling, if necessary with addition of extra $\mathrm{KBH}_{4}$, the gold is precipitated and can be filtered off.

Deposition rates are not constant but decrease with time, an effect which is in most instances a result of hydrolysis of the borohydride. While this can be compensated for by increasing borohydride concentrations, this also increases the rate at which the latter is lost by hydrolysis.

A typical bath has been described as showing a decrease of 27 per cent in deposition rate after storage at room temperature for thirty-two days.

Stirring effects are difficult to predict in autocatalytic plating reactions. In this instance, however, it was found that plating rates could be approximately doubled by stirring.

The useful life of a typical borohydride bath at the operating temperature, when used without replenishment, is limited to four to five hours, because of hydrolysis of the borohydride. The useful life can, however, be increased to twenty hours by replenishment, the limiting factors being apparently the effects of increasing metaborate ion and cyanide ion concentrations. Gold is preferably added in the form of $\mathrm{AuCN}$.

In the case of both gold and borohydride additions, these are preferably made below $40^{\circ} \mathrm{C}$.
Properties of Electroless Gold Plating from Borohydride Solutions

$\begin{array}{ll}\text { Adhesion } & \text { Excellent on metals } \\ \text { Appearance } & \text { Matt yellow } \\ \text { Density } & \text { Bulk gold }\left(19.3 \mathrm{~g} / \mathrm{cm}^{3}\right) \\ \text { Hardness } & \text { Soft (Knoop 60-80) } \\ \text { Porosity } & \text { Z Zero for deposits }>1 \mu \mathrm{m} \text { on } \\ & \text { uniform substrates } \\ \text { Purity } & >99.9 \%, 0,0001 \% \mathrm{~B} \\ \text { Resistivity } & \text { Bulk gold }(>0,03 \mathrm{ohm} / \mathrm{sq} \\ & \text { at } 1 \mu \mathrm{m}) \\ \text { T/C Bondability } & \text { Excellent }\end{array}$

The lack of any significant contamination with boron is to be noted.

Plating has been effected on gold, silver, copper, nickel, cobalt, iron, palladium, platinum, brass, Kovar, Permalloy and steel. Deposition also occurs on non-conductors such as glass and plastics, if these are sensitised with $\mathrm{SnCl}_{2}$ and activated with $\mathrm{PdCl}_{2}$.

Because of a tendency for nickel and copper to dissolve initially by galvanic displacement, this type of bath is apparently not suitable for deposition of gold on very thin films of copper or nickel.

The properties of the deposit are summarised in the table above (42).

\section{Gold as an Activator in the Plating of Plastics}

The sensitisation and activation processes as developed and applied up to 1968 in the autocatalytic plating of plastics have been described by Goldie (16).

In brief, the position is that a number of metals, including palladium, silver, gold and platinum have been found to initiate the autocatalytic deposition of other metals on plastics. Although at the present time palladium is used exclusively for this purpose, several authors (46-48) have nevertheless claimed gold to be technically superior to palladium in particular applications, and one investigator (49), reporting on the size of the microdeposits from gold and palladium systems, found that gold gave by far the finest deposits. The use of gold colloids for the activation of ABS plastic has also been investigated (50).

Although there are references $(46-49,51-61)$ in the patent literature to the use of gold as an activator for electroless plating of plastics, it does not seem to have enjoyed application in practice. The successful development of processes based on its use could therefore well create an important new application for gold and might well stimulate advances in the plating of plastics. 


\section{References}

1 A. Brenner and G. E. Riddell, f. Res. Nat. Btir. Stand., $1946,37,31$

2 G. Gutzeit, Plating, 1959, 46, 1158, 1275, 1377; 1960, 47, 63

3 D. J. Levy, Proc. Am. Electroplaters Soc., 1963, 50, 29

4 K. M. Gorbunova and A. A. Nikiforova, "Physical Principles of (Electroless) Nickel Plating", Acad. Sci. U.S.S.R., Inst. Phys. Chem., Moscow, 1960. Translated from Russian by the Israel Program for Scientific Translations, Jerusalem, 1963

5 M. Spiro, f. Chem. Soc., 1960, 3678

6 C. Wagner and W. Traud, Z. Electrochem., 1938, 44, 391

7 J. O'M. Bockris, "Modern Aspects of Electrochemistry", ed. J. O'M. Bockris and B. E. Conway, Butterworth, London, 1954, 253

8 M. Stern and A. L. Leary, F. Electrochem. Soc., 1957, 104, 56

9 M. Paunovic, Plating, 1968, 55, 1161

10 M. Spiro and A. B. Ravnö, F. Chem. Soc., 1965, 78

11 Y. Okinaka, f. Electrochem. Soc., 1973, 120, 739

12 N. Feldstein and P. R. Amodio, Plating, 1969, 56, 1246

13 R. Scholder and H. Heckel, $Z$. Anorg. Allgem. Chem., $1931,198,329$; cf ref. 4, p. 7

14 Y. Okinaka, "Gold Plating Technology", ed. F. H. Reid and W. Goldie, Electrochemical Publications, Ayr, Scotland, 1973, 82

15 T. Groenewald, $\mathcal{F}$. Appl. Electrochem, 1975, 5, 71

16 W. Goldie, Ed., "Metallic Coating of Plastics", Vol, I and II, Electrochemical Publications, Ayr, Scotland, 1969

17 S. D. Swan and E. L. Gostin, Metal Finish., 1961, $59,4,52$

18 J. L. Jostan and A. F. Bogenschutz, Plating, 1969, 56, 399

19 Y. Tanabe and H. Matsubayashi, f. Metal Finish. Soc. fapan, 1970, 21, 335, 436

20 A. Brenner, "Modern Electroplating", ed. F. A. Lowenheim, 2nd Ed., Wiley \& Sons, New York, 1963

21 R. R. Brookshire, U.S. Patent 2,976,181, 1961

22 T. Ezawa and H. Ito, Fapan Patent 40-1081, 1965; see ref. 14

23 T. Ezawa and H. Ito, fapan Patent 40-25881, 1968; see ref. 14

24 E. L. Gostin and S. D. Swan, U.S. Patent 3,032,436, 1962

25 B. M. Luce, U.S. Patent 3,300,328, 1967; see ref. 14

26 R. F. Walton, f. Electrochem. Soc., 1961, 108, (8), 767

27 D. S. Pokras, T. L. Sullens and R. F. Walton, U.S. Patent 3,123,484, 1964

28 F. W. Schnable, J. F. McCormack and R. J. Zeblinsky, U.S. Patent $3,468,676,1969$
29 T. Oda and K. Hayashi, U.S. Patent 3,506,462, 1970

30 R. Sard, Y. Okinaka and J. R. Rushton, Plating, 1971, 58, 893

31 Y. Okinaka and C. Wolowodiuk, Plating, 1971, 58, 1080

32 Y. Okinaka, F. Electrochem. Soc., 1973, 120, 739

33 Y. Okinaka, Plating, 1970, 57, 914

34 Y. Okinaka, R. Sard, C. Wolowodiuk, W. H. Craft and T. F. Retajezyk, $\mathcal{F}$. Electrochem. Soc., 1974, 121, 56

35 Y. Okinaka, R. Sard, W. H. Craft and C. Wolowodiuk, paper presented at Full Mtg. of Electrochem. Soc., Miami Beach, 1972

36 R. Sard, F. Electrachem. Soc., 1970, 117, 9

37 R. Sard, $\mathcal{F}$. Electrochem. Soc., 1970, 117, 1156

38 J. F. McCormack, U.S. Patent 3,589,916, 1971

39 D. W. Rich, Plating, 1971, 58; see ref. 14, p. 100

40 S. Wein, Metal Finish., 1948, 46, 8, 58; cf U.S. Rept. PB 111,332 , Office of Tech. Services, U.S. Dept. of Commerce, 1953

41 C. Gibson, Nature, 1937, 140, 279

42 N. Feldstein Plating, 1974, 61, 146

43 J. A. Gardiner and J. W. Collat, F. Am. Chem. Soc., 1964, 86, 3165

44 J. A. Gardiner and J. W. Collat, F. Am. Chem. Soc., $1965,87,1692$

45 J. A. Gardiner and J. W. Collat, Inorg. Chem., 1965, 4, 1208

46 E. B. Saubestre, U.S. Patent 2,872,359, 1959

47 H. Narcus, Proc. Am. Electroplaters Soc., 1956, 43, 157

48 F. Pearlstein, Metal Finish., 1955, 53, 59

$49 \mathrm{M}$. Matsunaga, Y. Hagiuda and K. Ito, Metal Finish $1968,66,80$

50 Fulmer Res. Inst., Confidential Repts. to Chamber of Mines of South Africa

51 A. E. Bergstrom, German Offen. 1,915,252, 1969

52 I. C. Hepfer, U.S. Patent 3,370,974, 1968

53 W. H. Young, B. Csuthy and J. Guidess (Timex Corp.) U.S. Patent 3,565,770, 1971

54 K. Heymann and G. Woldt (Schering A.G.), German Offen. 1,949,278, 1971

55 H. P. K. Hentzschel (Texas Instruments Inc.), German Offen. 1,949,754, 1970

56 D. G. Foulke and A. Simonian (Sel-Rex Corp.), U.S Patent 3,516,848, 1970

57 Sel-Rex Corp., British Patent 1,101,848, 1968

58 K. D. Baker (Silvercrown Ltd.), British Patent 1,193,823, 1970

59 N. B. Rajchenbaum (English Numbering Machines Ltd.), British Patent 1,122,235, 1970

60 Schering A. G., French Patent 1,553,827, 1969

61 G. Okuno and C. Yamauchi, Dutch Appl. 66.10976, 1967

\section{Gold Plating from a Thiosulphate Bath}

Sulphite electrolytes have gained considerable ground by comparison with the more established cyanide solutions for gold plating over the last few years, but another new type of electrolyte, based on a thiosulphate complex, has been developed for use in the gold plating of printed circuits in Poland. In a paper presented to the recent annual conference of the Institute of Metal Finishing in London, Professor Tadeusz Zak, Director of the Institute of Precision Mechanics in Warsaw, and two of his colleagues, Dr. Jan Socha and S. Safarzynski, gave details of this solution and of the cathodic and anodic processes occurring during deposition.
The bath finally formulated contained $20 \mathrm{~g} / 1$ gold in the form of a thiosulphate complex, $50 \mathrm{~g} / 1$ citric acid and $10 \mathrm{~g} / 1$ sodium tetraborate as buffer. The effects of temperature, $\mathrm{pH}$ and concentration of both gold and the complexing agent were studied, and optimum operating conditions were established. An operating temperature of $20^{\circ} \mathrm{C}$ with a pH of 9.0 to 10.0 were found to be most suitable.

The bath is said to be highly stable, to give a deposit of greater hardness than is obtained with a sulphite electrolyte, and to permit of a speed of deposition some two to five times greater than that usually associated with an acid cyanide bath. 